\title{
Study and Simulation of a Sensor Based on 2D Photonic Crystals for the Detection of Aromatic Compounds: $\mathrm{C}_{6} \mathrm{H}_{5} \mathrm{I}, \mathrm{C}_{6} \mathrm{H}_{5} \mathrm{~F}$ and $\mathrm{C}_{6} \mathrm{H}_{5} \mathrm{Cl}$
}

\author{
Mehdi Ghoumazi ${ }^{*}$, Messaoud Hameurlain \\ Research Unit in Optics and Photonics (UROP), Center for the Development of Advanced Technologies (CDTA), University \\ of Setif-1, Setif 19000, Algeria
}

Corresponding Author Email: mghoumazi@CDTA.DZ

https://doi.org/10.18280/acsm.450409

Received: 9 July 2021

Accepted: 13 August 2021

\section{Keywords:}

photonic crystals, FEM, sensor, organic compounds

\begin{abstract}
A new study was presented on a new sensor based on two-dimensional photonic crystals (Phc's) to detect the following three organic materials: iodobenzene $\left(\mathrm{C}_{6} \mathrm{H}_{5} \mathrm{I}\right)$, fluorobenzene $\left(\mathrm{C}_{6} \mathrm{H}_{5} \mathrm{~F}\right)$, chlorobenzene $\left(\mathrm{C}_{6} \mathrm{H}_{5} \mathrm{Cl}\right)$. These materials have dielectric constants ( $\varepsilon r$ ) equal to $2.623 ; 2.140 ; 2.318$, respectively. The proposed sensor is a structure made of silicon rods submerged in air plus a ring resonator. The ring resonator is stuck between two horizontal waveguides. At the end of the ends of the structure there are four ports where port 1 and 2 belong to the top guide and port (3) and (4) the bottom one. In order to analyze the behavior of the sensor, a plane wave expansion approach (PWE) and the finite element method (FEM) are applied. Thanks to the MATLAB and COMSOL simulation software, we were able to obtain the following numerical results: the norm of the electric field, the total energy density and this last magnitude according to the refractive indices of the different organic materials used. We could observe variations in energy density for each material. So, this change is due to their refractive index which varies from one material to another. In this study, we have fixed the other parameters like the constant of the lattice "a" and the radius " $r$ " and we are interested in the dielectric constants $\left(\varepsilon_{r}\right)$ or more precisely the refractive index $(n)$, the latter proves that it is one of the important parameters for detection.
\end{abstract}

\section{INTRODUCTION}

In recent years, nanostructure materials have played an important role in scientific fields (for example: chemical analysis) as well as technological progress in photonic and optical applications $[1,2]$. A recent approach in analysis is to create sensors using photonic crystals $(\mathrm{PhC})[3,4]$. Also, several researchers have shown that it is possible to develop physical sensors using $\mathrm{PhCs}$ of different structures in order to complete biological sensors which tighten the detection of proteins, bacteria, toxins, viruses, DNA [5-7]; Or even temperature and mechanical pressure [8, 9]; similarly chemical sensors to detect organic solvents, molecules, vapors, small ions, or to find the $\mathrm{pH}$ and ionic strength of a solution [10-13]. Photonic crystals $(\mathrm{PhC})$ are man-made materials made up of a periodic arrangement in which the refractive index (the dielectric constant) at a periodicity which can vary across three dimensions and this can allow light to be controlled for its photonic band gap (PBG) and / or its light diffraction properties [14-17]. By their periodicities and their properties, photonic crystals make it possible to make optical or electromagnetic devices capable of storing, filtering or guiding light at the wavelength scale. Photonic crystals are often used in telecommunications and computing [18] especially in the field of integrated optics. Also, the use of photonic crystals in other applications is developing as for: solar with improved efficiency of photovoltaic cells [18], lasers with the optimization of their performance for low threshold lasers [19], lithium-ion batteries to increase their efficiency [20], biological or chemical sensors for detection [21]. In order to have different optical devices based on PhCs which can be developed; suitable defects have been created such as, optical converters [22], optical waveguides [23], optical switches [24], optical power dividers [25], optical filters $[26,27]$ as well as sensors [28]. A few years ago, square and triangular network channel drop filter (CDF) ring resonators were studied by two researchers David and Abrishamian. Their work is based on a multi-channel drop filter with PhcRR using two different refractive indices in 2D -PhC with a square grating [29].

In parallel another team of Mehdizadeh et al studied the effect of several parameters such as the refractive index of dielectric rods and so on ... which are important parameters for the adjustment of the filter [30].

In this article, we will use the Channel Drop Filter (CDF) design based on a new 2D photonic crystal-based ring resonator setup to build a new sensor to detect three aromatic compounds $\mathrm{C}_{6} \mathrm{H}_{5} \mathrm{I}, \mathrm{C}_{6} \mathrm{H}_{5} \mathrm{~F}$ and $\mathrm{C}_{6} \mathrm{H}_{5} \mathrm{Cl}$ from the benzene family (see Figure 1) [31-33].

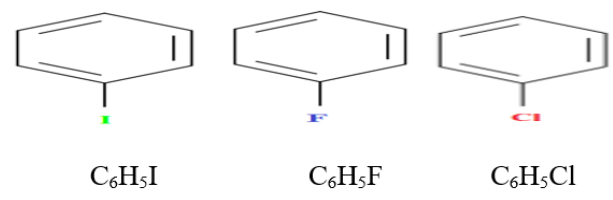

Figure 1. Chemical compound of Iodobenzene $\left(\mathrm{C}_{6} \mathrm{H}_{5} \mathrm{I}\right)$, Fluorobenzene $\left(\mathrm{C}_{6} \mathrm{H}_{5} \mathrm{~F}\right)$ and Chlorobenzene $\left(\mathrm{C}_{6} \mathrm{H}_{5} \mathrm{Cl}\right)$ 


\section{SENSOR DESIGN}

Two methods are exploited in this study, one is the plane wave expansion (PWE) to extract the photonic band gap (PBG) and the other is a digital method integrated in the simulation software COMSOL in order to have the following physical parameters: the distribution of the refractive index ' $n$ ' and the mesh along the structure. Also, the electric field for the various organic compounds proposed. Next, we presented the total energy density (TED) as a function of the cross section line $x$ for the three organic compounds. We end this study by presenting the total energy density (TED) as a function of the important parameter " $n$ " for the three proposed materials.

Within the proposed structure some modifications have been made in order to have a ring resonator. Figure 2 illustrates the final shape of a resonator wedged between two parallel waveguides; one is at the top created by removing a full row of dielectric rods in the $\Gamma$-M direction to create the bus waveguide and the second below by removing a full row in the $\Gamma-\mathrm{M}$ direction to create the guide output waves.

The proposed sensor is made from the two-dimensional photonic crystal of a square lattice form submerged in air from which there are 35 dielectric rods horizontally and 28 dielectric rods vertically. Knowing that the dielectric constant of the rods (cr) is 11.9716 and for air is equal to " $1 "$ as well as the radius of the perfect $\mathrm{PhC}$ rods (without defect) is $\mathrm{r}=0.19 \mathrm{a}$.

Knowing that the refractive index ' $n$ ' and the dielectric constant of the material ' $\varepsilon_{\mathrm{r}}$ ' is linked by this formula:

$$
\varepsilon_{\mathrm{r}}=\mathrm{n}^{2}
$$
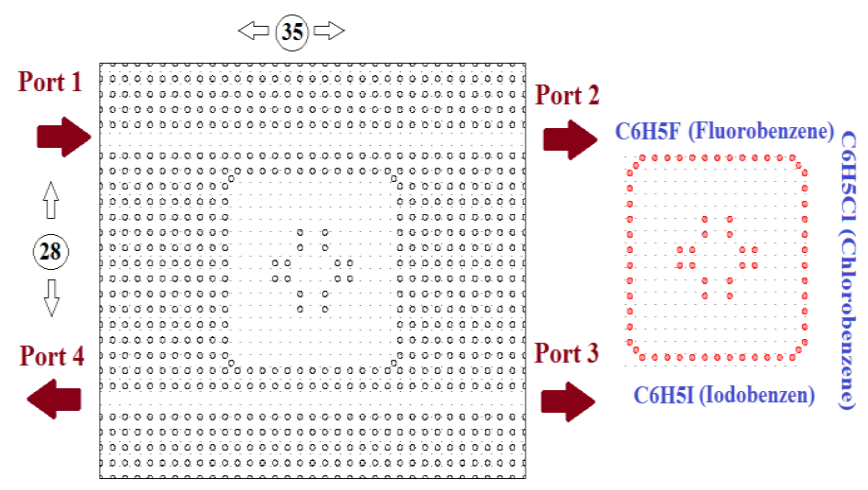

Figure 2. The final sketch of sensor

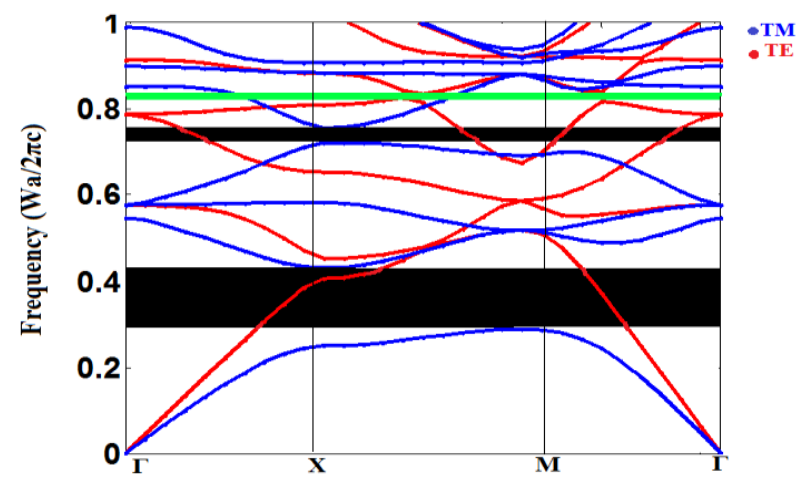

Figure 3. Photonic band gap of the sensor

For a good superior compatibility with optical communications intervals, we have taken $a=623 \mathrm{~nm}$ from where the study will be extended in a wavelength interval around $1415 \mathrm{~nm}$ and $1946 \mathrm{~nm}$ in TM mode.

As it was explained, to realize the sensor in a fundamental platform, we suppressed a complete row of dielectric rods in the direction $\Gamma-\mathrm{M}$, and some rods in the direction $\Gamma-\mathrm{M}$ we created respectively the guide of guide bus waves and the waveguide output.

Subsequently, we created a resonant ring between the two guides. So, we removed from a $15 \times 15$ array of dielectric rods at the appropriate location of the rods to create a shape in the heart of the resonator. We have not varied the radius within this form and it will remain of the same value as in all the other rods of the initial structure Phc. The final schematic diagram of the proposed sensor is shown in Figure 3.

The sensor we have proposed has four ports rated from 1 to 4 ,

- $\quad$ The waveguide input port is marked as port (1);

- The output waveguide is marked as port (2) and called as the forward transmission terminal.

- The waveguide of ports (3) and (4) are designated as forward descent.

The optical waves entering the structure take a path which goes from the port (1) to the exit of the port (2) and thanks to the desired length this will allow them to take another path passing through the resonator in resonant ring towards the last name named port (4).

In addition, as shown in Figure 1, the refractive index of the frame surrounding the resonator has been changed by various organic compounds of the benzene family such as, fluorobenzene $\left(\mathrm{C}_{6} \mathrm{H}_{5} \mathrm{~F}\right)$ [32], chlorobenzene $\left(\mathrm{C}_{6} \mathrm{H}_{5} \mathrm{Cl}\right)$ [34] and iodobenzene $\left(\mathrm{C}_{6} \mathrm{H}_{5} \mathrm{I}\right)[35,36]$. The modified refractive indices are in red as shown in Figure 1.

\section{RESULTS AND DISCUSSION}

We started with the extraction of the PBG then the propagation of the electric field (E) and the calculation of the total energy density (T.E.D) using the PWE method and the finite element method (F.E.M). Basically, solving Maxwell's equations (E.M) allowed us to study the propagation of electromagnetic waves in a photonic crystal structure where the form of the magnetic field is written as:

$$
\nabla \times\left(\frac{1}{\varepsilon(\vec{r})} \nabla \times H(\vec{r})\right)=\left(\frac{\omega}{c}\right)^{2} H(\vec{r})
$$

The angular frequency is ' $\omega$ ', the speed of light in vacuum is noted ' $\mathrm{c}$ ' and $\varepsilon(\mathrm{r})$ is relative permittivity of material.

The FEM calculation is applied for the dispersion relation of square lattice pattern for TE and TM polarizations and on the (xy) plane of the square lattice structure the light propagates. The PBGs of the Phe with aforementioned values is depicted in Figure 2. In the following part, our simulations are adapted to the proposed structure based on a $2 \mathrm{D}$ photonic crystal ring resonator called sensor.

Figure 3 illustrates the photonic band gap (PBG) of the sensor for TE and TM modes. We observe three PBGs, one for the TE mode which is narrow (green color) and two other bands of the TM mode (black color). These last two bands have a medium and wide opening. The three bands are in an interval of $0.85<\mathrm{a} / \lambda<0.86$ for the TE mode and for the TM mode, the middle band is at $0.77<\mathrm{a} / \lambda<0.78$ and the band largest at $0.32<\mathrm{a} / \lambda<0.44$ 
The widest band gap of the TM mode will be of interest because it is large enough to cover sufficient wavelengths for optical communication applications.

Our numerical results are extracted using COMSOL software, as they are generated by the finite element method which is integrated into this software. Through this study, we have illustrated the distribution of the refractive index as well as the mesh along the structure followed by the study of the distribution of the norm of the electric field. And the total energy density (TED) as a function of the transverse line plus the TED as a function of the refractive index " $n$ " for the three organic compounds which are fluorobenzene $\left(\mathrm{C}_{6} \mathrm{H}_{5} \mathrm{~F}\right)$, chlorobenzene $\left(\mathrm{C}_{6} \mathrm{H}_{5} \mathrm{Cl}\right)$ and iodobenzene $\left.\left(\mathrm{C}_{6} \mathrm{H}_{5} \mathrm{I}\right)\right)$ in a twodimensional square lattice structure based on photonic crystals. The plane of propagation of the electromagnetic wave is $(\mathrm{xz})$. This wave is the telecommunications wavelength, $1.55 \mu \mathrm{m}$.

Figures 4-6 show the distribution of the refractive index (n), the mesh over the entire structure as well as the distribution of the electric field at resonance $(\lambda=1.550 \mu \mathrm{m})$ for the following different organic compounds: $\mathrm{C}_{6} \mathrm{H}_{5} \mathrm{~F}, \mathrm{C}_{6} \mathrm{H}_{5} \mathrm{Cl}$ and $\mathrm{C}_{6} \mathrm{H}_{5} \mathrm{I}$, respectively.

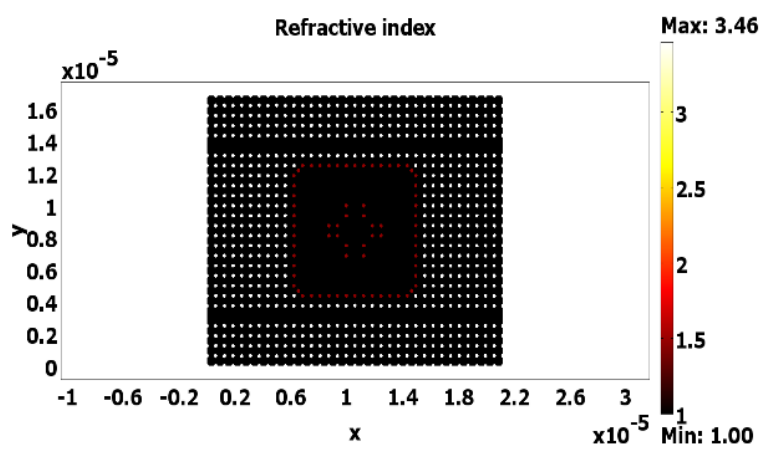

Figure 4. Distribution of the refractive index ' $n$ ' along the sensor
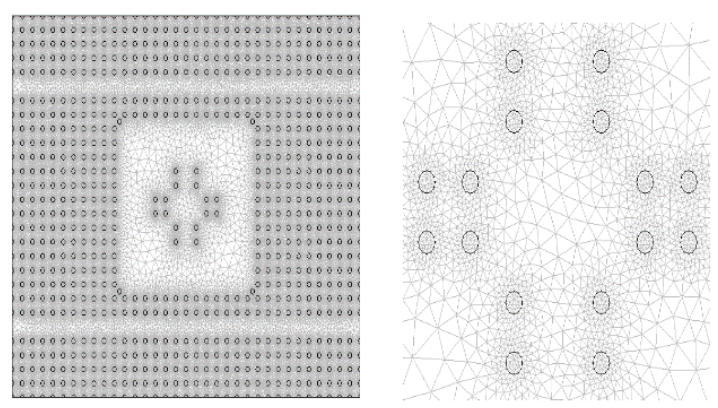

Figure 5. The sensor with mesh

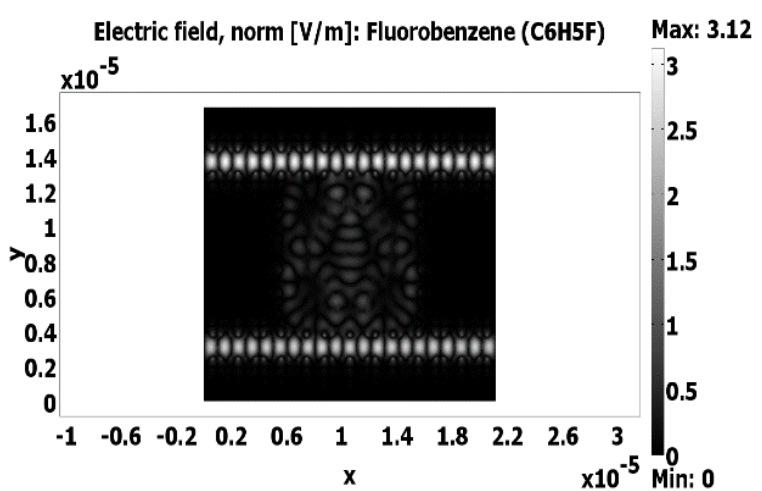

(a) Fluorobenzene $\left(\mathrm{C}_{6} \mathrm{H}_{5} \mathrm{~F}\right)$

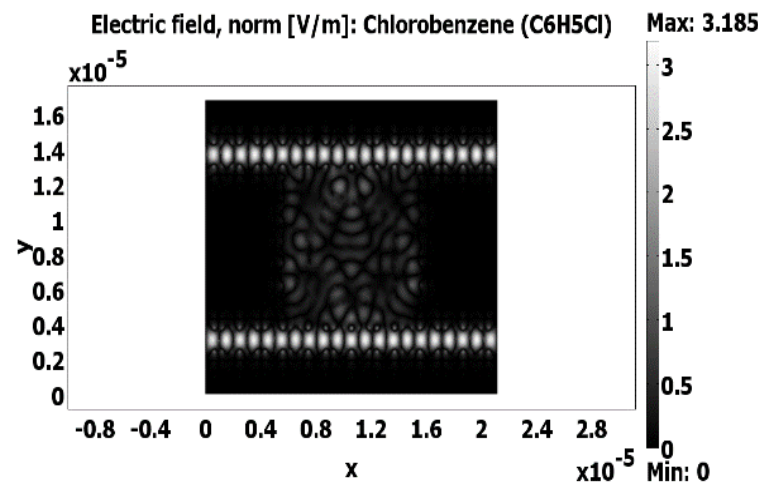

(b) Chlorobenzene $\left(\mathrm{C}_{6} \mathrm{H}_{5} \mathrm{Cl}\right)$

Electric field, norm [V/m]: Iodobenzene (C6H5I) Max: 4.898

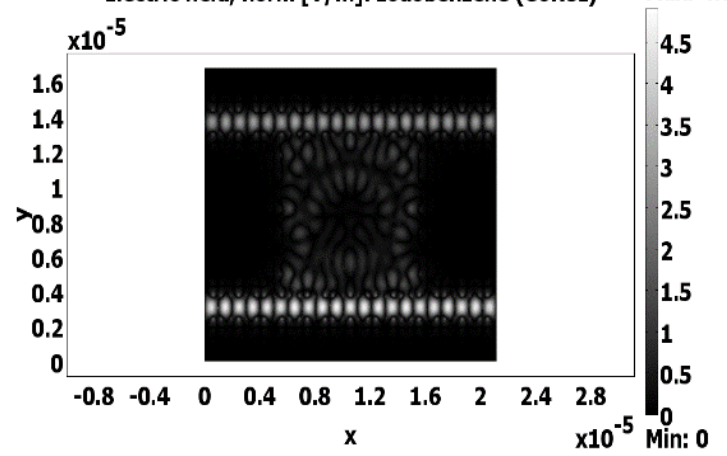

(c) Iodobenzene $\left(\mathrm{C}_{6} \mathrm{H}_{5} \mathrm{I}\right)$

Figure 6. Electric field distribution for different refractive index of (a) Fluorobenzene $\left(\mathrm{C}_{6} \mathrm{H}_{5} \mathrm{~F}\right)$, (b) Chlorobenzene $\left(\mathrm{C}_{6} \mathrm{H}_{5} \mathrm{Cl}\right)(\mathrm{c})$ Iodobenzene $\left(\mathrm{C}_{6} \mathrm{H}_{5} \mathrm{I}\right)$, respectively at $\lambda=$ $1.550 \mu \mathrm{m}$

The function expression of time average total energy density is:

$$
W_{a v}=W_{e}^{a v}+W_{m}^{a v}
$$

where, $W_{e}^{a v}$ represent time average electric energy density and its expression is:

$$
W_{e}^{a v}=\frac{1}{4} R_{e}\left(E \cdot D^{*}\right)
$$

And $W_{m}^{a v}$ represent time average magnetic energy density and its expression is:

$$
W_{m}^{a v}=\frac{1}{4} R_{e}\left(H_{z} \cdot B_{z}\right)
$$

Then:

$$
W_{a v}=\frac{1}{4} R_{e}\left(E \cdot D^{*}\right)+\frac{1}{4} R_{e}\left(H_{z} \cdot B_{z}\right)
$$

where, the unity of $W_{a v}$ is $\mathrm{J} / \mathrm{m}^{3}$

In addition, from Figure 7, we show the behaviour of the total energy density (TED) of the three proposed organic compounds which are fluorobenzene $\left(\mathrm{C}_{6} \mathrm{H}_{5} \mathrm{~F}\right)$, chlorobenzene $\left(\mathrm{C}_{6} \mathrm{H}_{5} \mathrm{Cl}\right)$ and iodobenzene $\left(\mathrm{C}_{6} \mathrm{H}_{5} \mathrm{I}\right)$ at resonance $(\lambda=1.55 \mu \mathrm{m})$ with refractive indices 1.4626 for flurobenzene, 1.5226 for chlorobenzene and 1.6196 for iodobenzene. Note that the three curves obtained will reach maximums. The greatest total energy density transferred from port 1 to port 2 is that of chlorobenzene for a maximum of $2.08 * 10^{-15} \mathrm{~J} / \mathrm{m}^{3}$. Then, the 
total energy density of iodobenzene will be just below for a maximum of $1.83 * 10^{-15} \mathrm{~J} / \mathrm{m}^{3}$ and the last curve which will be a little lower concerns fluorobenzene for a maximum of $1.736 * 10^{-15} \mathrm{~J} / \mathrm{m}^{3}$. These are three maximum curves that coincide with the same cross section line at $1.06^{*} 10^{-5} \mathrm{~m}$.

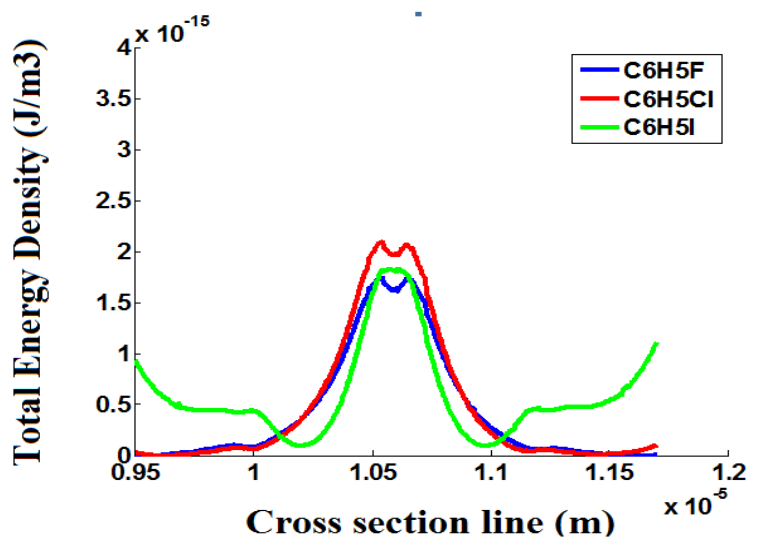

Figure 7. The total energy density of: Fluorobenzene $\left(\mathrm{C}_{6} \mathrm{H}_{5} \mathrm{~F}\right)$, Chlorobenzene $\left(\mathrm{C}_{6} \mathrm{H}_{5} \mathrm{Cl}\right)$ and Iodobenzene $\left(\mathrm{C}_{6} \mathrm{H}_{5} \mathrm{I}\right)$ versus cross section line

Figure 8 illustrates the total energy density (TED) curve for the different materials used as a function of their refractive index. This figure can express a relevant idea on how to detect these organic compounds. So, high energy density Chlorobenzene is the first organic compound to be detected for an average refractive index $(n=1.5226)$ then it will be followed by Iodobenzene which has an average energy density for a high refractive index $(\mathrm{n}=1.6196)$. And finally, Fluorobenzene manifests itself by a very low total energy density for a low refractive index too $(n=1.4626)$ compared to other materials.

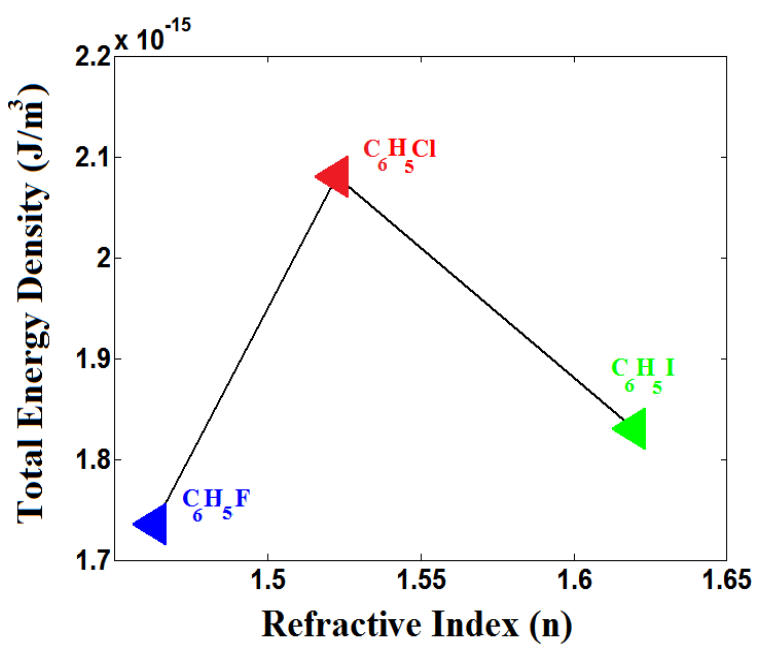

Figure 8. The total energy density of: Fluorobenzene $\left(\mathrm{C}_{6} \mathrm{H}_{5} \mathrm{~F}\right)$, Chlorobenzene $\left(\mathrm{C}_{6} \mathrm{H}_{5} \mathrm{Cl}\right)$ and Iodobenzene $\left(\mathrm{C}_{6} \mathrm{H}_{5} \mathrm{I}\right)$ versus refractive index

\section{CONCLUSION}

In this work, we proposed a 2D photonic crystal-based sensor for the detection of organic compounds. For this we hollowed out in the initial structure two horizontal waveguides plus a resonator which is located between these two guides.
Then, the silicon resonator rods were replaced each time by the organic compounds studied such as fulorobenzene $\left(\mathrm{C}_{6} \mathrm{H}_{5} \mathrm{~F}\right)$, chlorobenzene $\left(\mathrm{C}_{6} \mathrm{H}_{5} \mathrm{Cl}\right)$ and iodobenzene $\left(\mathrm{C}_{6} \mathrm{H}_{5} \mathrm{I}\right)$ which has the refractive indices $1.4629,1.5226$ and 1.6196 respectively. From the simulation results obtained, we were able to observe total energy density (TED) curves which vary according to the indices of the proposed materials. This variation in physical quantities (TED) is due to the refractive index " $n$ " which varies from one organic compound to another. This " $n$ " index appears to be an important parameter for the detection of organic compounds. Therefore, it will be authorized as biosensors in several research fields such as: medical, environment, etc.

\section{REFERENCES}

[1] Fraga, M.A. (2020). Nanostructured materials. MRS Bulletin, 45(10): 867-868. https://doi.org/10.1557/mrs.2020.263

[2] Paquet, C., Kumacheva, E. (2008). Nanostructured polymers for photonics. Materials Today, 11(4): 48-56. https://doi.org/10.1016/S1369-7021(08)70056-7

[3] Li, J., Wang, H., Dong, S., Zhu, P., Diao, G., Yang, Z. (2014). Quantum-dot-tagged photonic crystal beads for multiplex detection of tumor markers. Chemical Communications, 50(93): 14589-14592. https://doi.org/10.1039/C4CC07019D

[4] Shen, W., Li, M., Wang, B., Liu, J., Li, Z., Jiang, L., Song, Y. (2012). Hierarchical optical antenna: Gold nanoparticle-modified photonic crystal for highlysensitive label-free DNA detection. Journal of Materials Chemistry, 22(16): 8127-8133. https://doi.org/10.1039/C2JM16655K

[5] Goyal, A.K. (2020). Design analysis of one-dimensional photonic crystal based structure for hemoglobin concentration measurement. Progress In Electromagnetics Research M, 97: 77-86. https://doi.org/10.2528/PIERM20080601

[6] Shafiee, H., Lidstone, E.A., Jahangir, M., Inci, F., Hanhauser, E., Henrich, T.J., Demirci, U. (2014). Nanostructured optical photonic crystal biosensor for HIV viral load measurement. Scientific Reports, 4(1): 17. https://doi.org/10.1038/srep04116

[7] Troia, B., Paolicelli, A., De Leonardis, F., Passaro, V.M. (2013). Photonic crystals for optical sensing: A review. Advances in Photonic Crystals, 241-295. https://doi.org/10.5772/53897

[8] Abadla, M.M., Elsayed, H.A., Mehaney, A. (2020). Novel design for the temperature sensing using annular photonic crystals. Silicon, 1-9. https://doi.org/10.1007/s12633-020-00788-5

[9] Lakshmi, D.L., Kolli, V.R., Srikanth, P.C., Girijamba, D.L., Bahaddur, I. (2021). Pressure sensor based on twodimensional photonic-crystal ring resonator. Advances in VLSI, Signal Processing, Power Electronics, IoT, Communication and Embedded Systems: Select Proceedings of VSPICE 2020, 752: 85. https://doi.org/10.1007/978-981-16-0443-0_7

[10] Fenzl, C., Hirsch, T., Wolfbeis, O.S. (2012). Photonic crystal based sensor for organic solvents and for solventwater mixtures. Sensors, 12(12): 16954-16963. https://doi.org/10.3390/s121216954

[11] Chen, Y., Fegadolli, W.S., Jones, W.M., Scherer, A., Li, 
M. (2014). Ultrasensitive gas-phase chemical sensing based on functionalized photonic crystal nanobeam $\begin{array}{lll}\text { cavities. } & \text { ACS Nano, } & \text { 522-527. }\end{array}$ https://doi.org/10.1021/nn4050547

[12] Fenzl, C., Wilhelm, S., Hirsch, T., Wolfbeis, O.S. (2013). Optical sensing of the ionic strength using photonic crystals in a hydrogel matrix. ACS Applied Materials \& Interfaces, $\quad 5(1)$ : 173-178. https://doi.org/10.1021/am302355g

[13] Li, C., Lotsch, B.V. (2012). Stimuli-responsive 2D polyelectrolyte photonic crystals for optically encoded pH sensing. Chemical Communications, 48(49): 61696171. https://doi.org/10.1039/C2CC31916K.

[14] Ghoumazi, M., Hocini, A. (2021). Photonic crystal based bio-sensor detection in nanophotonic structure using FEM method. International Journal of Sensors Wireless Communications and Control, 11(2): 216-224. https://doi.org/10.2174/2210327910666191218125109

[15] Moukhtari, R., Hocini, A., Khedrouche, D. (2016). Study of two-dimensional photonic crystal microcavities as a function of refractive index. Acta Physica Polonica, A, 129(4): 556-558 https://doi.org/10.12693/APhysPolA.129.556

[16] Ghoumazi, M., Hocini, A., Hameurlain, M. (2018). Study and simulation of the power flow distribution of an optical channel drop filter in structure based on photonic crystal ring resonator for different organic liquids. In International Conference in Artificial Intelligence in Renewable Energetic Systems, pp. 544-551. https://doi.org/10.1007/978-3-030-04789-4_58

[17] Nair, R.V. (2020). Light transport in three-dimensional photonic crystals. Nano-Optics: Fundamentals, Experimental Methods, and Applications, 197. https://doi.org/10.1016/B978-0-12-818392-2.00008-1

[18] Fan, S., Villeneuve, P.R., Joannopoulos, J.D., Haus, H.A. (1998). Channel drop filters in photonic crystals. Optics Express, $3(1)$ : 4-11. https://doi.org/10.1364/OE.3.000004

[19] Zhang, H., Yu, X., Braun, P.V. (2011). Threedimensional bicontinuous ultrafast-charge and-discharge bulk battery electrodes. Nature Nanotechnology, 6(5): 277-281. https://doi.org/10.1038/nnano.2011.38

[20] Gomyo, A., Ushida, J., Shirane, M. (2006). Highly dropefficient channel-drop optical filters with Si-based photonic crystal slabs. Thin Solid Films, 508(1-2): 422425. https://doi.org/10.1016/J.TSF.2005.06.113

[21] Ellis, B., Mayer, M.A., Shambat, G., Sarmiento, T., Harris, J., Haller, E.E., Vučković, J. (2011). Ultralowthreshold electrically pumped quantum-dot photoniccrystal nanocavity laser. Nature Photonics, 5(5): 297-300. https://doi.org/10.1038/nphoton.2011.51

[22] Gandhi, S.I., Sridarshini, T. (2019). Design of photonic crystal based optical digital to analog converters. Laser Physics, 29(4): 046206. https://doi.org/10.1088/1555$6611 / \mathrm{ab} 05 \mathrm{~d} 1$

[23] Iqbal, M., Zhao, D., Ma, Y., Zhong, K. (2020). Designing optical waveguides: Myth and reality. Brazilian Journal of Physics, 50: 857-873. https://doi.org/10.1007/s13538020-00763-w

[24] Rutckaia, V., Schilling, J. (2020). Ultrafast low-energy all-optical switching. Nature Photonics, 14(1): 4-6. https://doi.org/10.1038/s41566-019-0571-7

[25] Esmaieli, A., Ghayour, R. (2012). Magneto-optical photonic crystal $1 \times 3$ switchable power divider. Photonics and Nanostructures-Fundamentals and Applications, 10(1): 131-139. https://doi.org/10.1016/j.photonics.2011.09.002

[26] Mehdi, G., Hocini, A., Hameurlain, M., Boudaa, M. (2018). Novel design of optical sensor based on twodimensional photonic crystals for the detection of volatile organic compounds that can infect human health. Medical Technologies Journal, 2(4): 293-300. https://doi.org/10.26415/2572-004X-vol2iss4p293-300

[27] Seifouri, M., Fallahi, V., Olyaee, S. (2018). Ultra-highQ optical filter based on photonic crystal ring resonator. Photonic Network Communications, 35(2) : 225-230. https://doi.org/10.1007/s11107-017-0732-x

[28] Mehdi, G., Hocini, A. (2019). Design of Bio-alcohol Sensor Based on Two-Dimensional Photonic Crystal in a Nanophotonic Structure. In 2019 International Conference on Advanced Electrical Engineering (ICAEE). pp. https://doi.org/10.1109/ICAEE47123.2019.9015129

[29] Taalbi, A., Bassou, G., Mahmoud, M.Y. (2013). New design of channel drop filters based on photonic crystal ring resonators. Optik, 124(9): 824-827. https://doi.org/10.1016/j.ijleo.2012.01.045

[30] Mehdizadeh, F., Alipour-Banaei, H., Serajmohammadi, S. (2013). Channel-drop filter based on a photonic crystal ring resonator. Journal of Optics, 15(7): 075401. https://doi.org/10.1088/2040-8978/15/7/075401

[31] Kavita, K., Das, P.K. (2002). Photodissociation of $\mathrm{C}_{6} \mathrm{H}_{5} \mathrm{I}$, $\mathrm{C}_{6} \mathrm{~F}_{5} \mathrm{I}$, and related iodides in the ultraviolet. The Journal of Chemical Physics, 117(5): 2038-2044. https://doi.org/10.1063/1.1489416

[32] Albert, S., Keppler, K., Quack, M. (2015). Highresolution rovibrational spectroscopy of fluorobenzene, C6H5F: analysis of the B 1 fundamentals $v 4, v 10 \mathrm{~b}, v 17$ $\mathrm{b}$, the B 2 fundamental $v 15$ and assignment of the A 1 levels $v 12,2 v 16$ a and $2 v 18$ b. Molecular Physics, 113(15-16): 2267-2289. http://dx.doi.org/10.1080/00268976.2015.1023754

[33] Dhami, D.S., Joshi, B., Dhami, G.B., Bista, S., Joshi, B.D. (2019). First principle study of chlorobenzene. Himalayan Physics, 8: 19-26. https://doi.org/10.3126/hp.v8i0.29942

[34] Wang, J.D., Mei, Y., Liu, C.L., Chen, J.M. (2008). Chlorobenzene degradation by electro-heterogeneous catalysis in aqueous solution: intermediates and reaction mechanism. Journal of Environmental Sciences, 20(11): 1306-1311. 0742(08)62226-3

[35] Syomin, D., Koel, B.E. (2001). Adsorption of iodobenzene $\left(\mathrm{C}_{6} \mathrm{H}_{5} \mathrm{I}\right)$ on $\mathrm{Au}\left(\begin{array}{lll}1 & 1 & 1\end{array}\right)$ surfaces and production of biphenyl $\left(\mathrm{C}_{6} \mathrm{H}_{5}-\mathrm{C}_{6} \mathrm{H}_{5}\right)$. Surface Science, 490(3): 265-273. https://doi.org/10.1016/S00396028(01)01319-X

[36] Taneja, N., Peddinti, R.K. (2016). Iodobenzene and mchloroperbenzoic acid mediated oxidative dearomatization of phenols. Tetrahedron Letters, 57(35): 3958-3963.

http://dx.doi.org/10.1016/j.tetlet.2016.07.078 